\title{
DIGITALLY PROGRAMMABLE INTEGRATOR AND DIFFERENTIATOR
}

\author{
ABDULRAHMAN KHALAF AL-ALI, MUHAMMAD TAHER \\ ABUELMA'ATTI AND SYED YUNUS \\ King Fahd University of Petroleum and Minerals, Box 203, Dhahran 31261, Saudi Arabia \\ (Received August 14, 1994; in final form September 7, 1994)
}

\begin{abstract}
Digitally programmable integrator and differentiator circuits are presented. Each circuit uses at most one operational amplifier, two operational transconductance amplifiers, and one capacitor. The time constants of the circuits are decided by the biasing currents of the operational transconductance amplifiers. The circuits can be easily interfaced with microprocessor-based systems. Experimental results are included.
\end{abstract}

\section{INTRODUCTION}

The operational transconductance amplifier (OTA) provides highly linear electronic tunability of its transfer gain $\left(\mathrm{g}_{\mathrm{m}}\right)$, requires just a few or even no resistors for its internal circuitry, and has more reliable high-frequency performance than that of the operational amplifier. This justifies the growing interest in designing OTA-based circuits [see for example 1-5 and the references cited therein]. The purpose of this paper is to investigate the feasibility of designing digitally programmable OTAbased integrators and differentiators.

\section{PROPOSED CIRCUITS}

Figures 1-3 show the proposed circuits for providing digitally programmable integrators and/or differentiators.

For the circuit of Fig. 1 the transfer function of the integrator is given by

$\frac{\nu_{\mathrm{o}}}{\nu_{\mathrm{i}}}=\frac{1}{1+\mathrm{sC} / \mathrm{g}_{\mathrm{m} 1}}$

where $g_{m 1}$ is the transconductance of the OTAs. From (1), one can see that the time-constant of the integrator is equal to $\mathrm{C} / \mathrm{g}_{\mathrm{m} 1}$ while its dc gain is equal to unity. The two biasing resistors $R_{B 1}$ provide the biasing currents to the two OTAs. Since the transconductance is proportional to the bias current $\left(\mathrm{I}_{\mathrm{B} 1}\right)$, then controlling the bias voltage, which can be obtained from the output of a digital-to-analog converter (DAC), results in changing $g_{m}$ which, in turn, changes the time-constant of the integrator. 


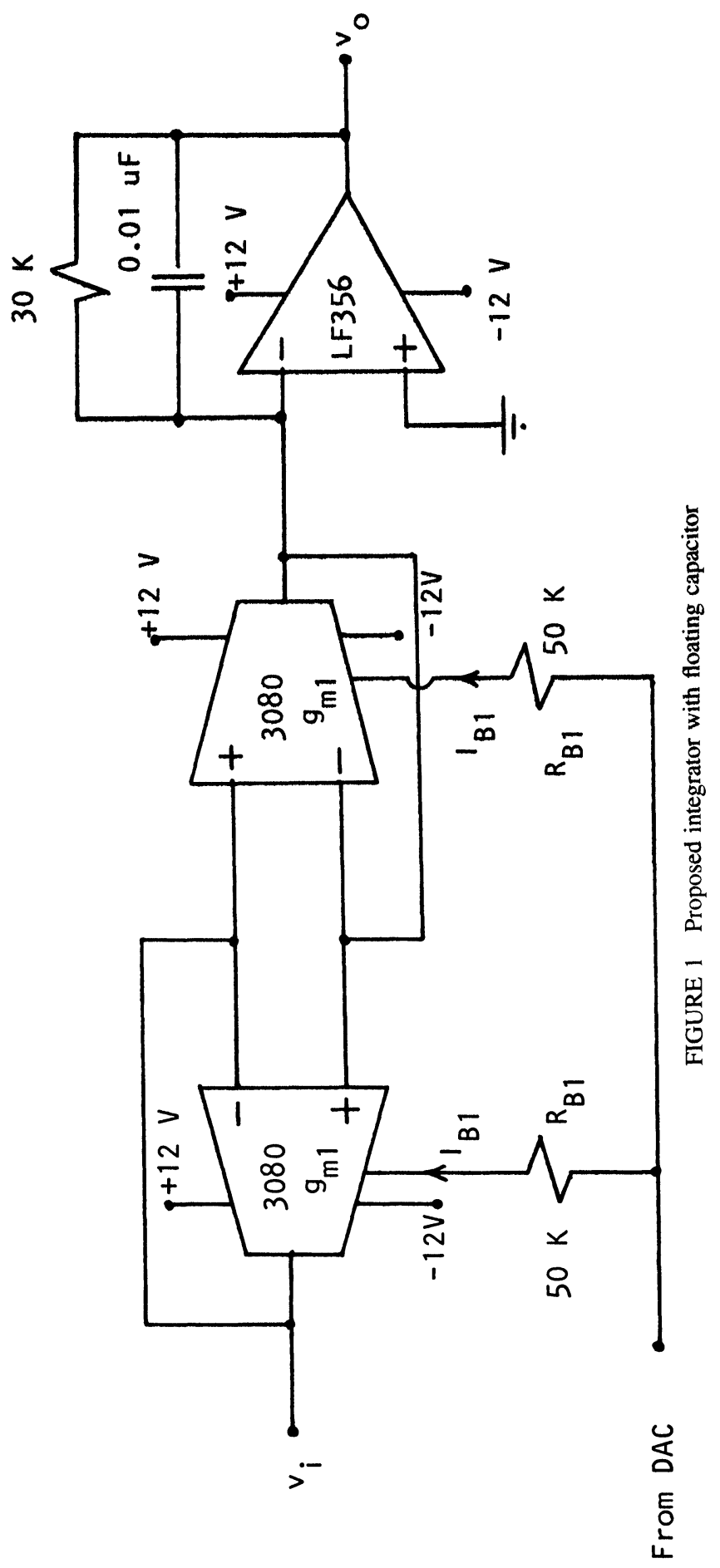


For the circuit of Fig. 2 the transfer function of the integrator is given by ${ }^{1}$

$\frac{\nu_{\mathrm{o}}}{\nu_{\mathrm{i}}}=\frac{\mathrm{g}_{\mathrm{m} 3} / \mathrm{g}_{\mathrm{m} 2}}{1+\mathrm{sC} / \mathrm{g}_{\mathrm{m} 2}}$

From (2), one can see that the time-constant of this integrator is equal to $\mathrm{C} / \mathrm{g}_{\mathrm{m} 2}$ while its dc gain is equal to $\mathrm{g}_{\mathrm{m} 3} / \mathrm{g}_{\mathrm{m} 2}$. Thus, both the time-constant and the dc gain are digitally programmable. First, the time constant can be adjusted by changing $\mathrm{g}_{\mathrm{m} 2}$ and then the dc gain can be adjusted by changing $\mathrm{g}_{\mathrm{m} 3}$. It is interesting to note that this integrator uses only two OTAs and one capacitor. Thus, its implementation in CMOS technology is feasible. ${ }^{1}$

For the circuit of Fig. 3, the transfer function of the differentiator is given by

$\frac{\nu_{\mathrm{o}}}{\nu_{\mathrm{i}}}=\frac{1}{1+\mathrm{g}_{\mathrm{m} 4} / \mathrm{sC}}$

From (3), one can see that the time-constant of the differentiator is equal to $\mathrm{C} / \mathrm{g}_{\mathrm{m} 4}$ while its dc gain is unity. Thus, the time-constant can be adjusted by changing $\mathrm{g}_{\mathrm{m} 4}$.

\section{EXPERIMENTAL RESULTS}

The circuits of Figs. 1-3 were tested experimentally. Digital programming is achieved by controlling the transconductances of the OTAs using the output of a digital-to-analog converter. The input of this DAC is obtained from a keyboard. The circuits were built using the CA3080 OTA, the LF356 operational amplifier, and the MC1408 DAC. Fig. 4 shows the pin connections of the DAC. Typical results are shown in Fig. 5. The time constant was successfully controlled from the keyboard.

\section{CONCLUSION}

In this paper, digitally programmable OTA-based integrators and differentiators have been presented. The time-constant of these circuits can be controlled by controlling the bias currents of the OTAs. By obtaining these bias currents from the output of a DAC, the time constants can be digitally programmed. The proposed circuits uses the minimum number of resistors for controlling the bias currents and, therefore, are very attractive for integration. The integrator of Fig. 2 uses a grounded capacitor. This is another attractive feature for integration. 


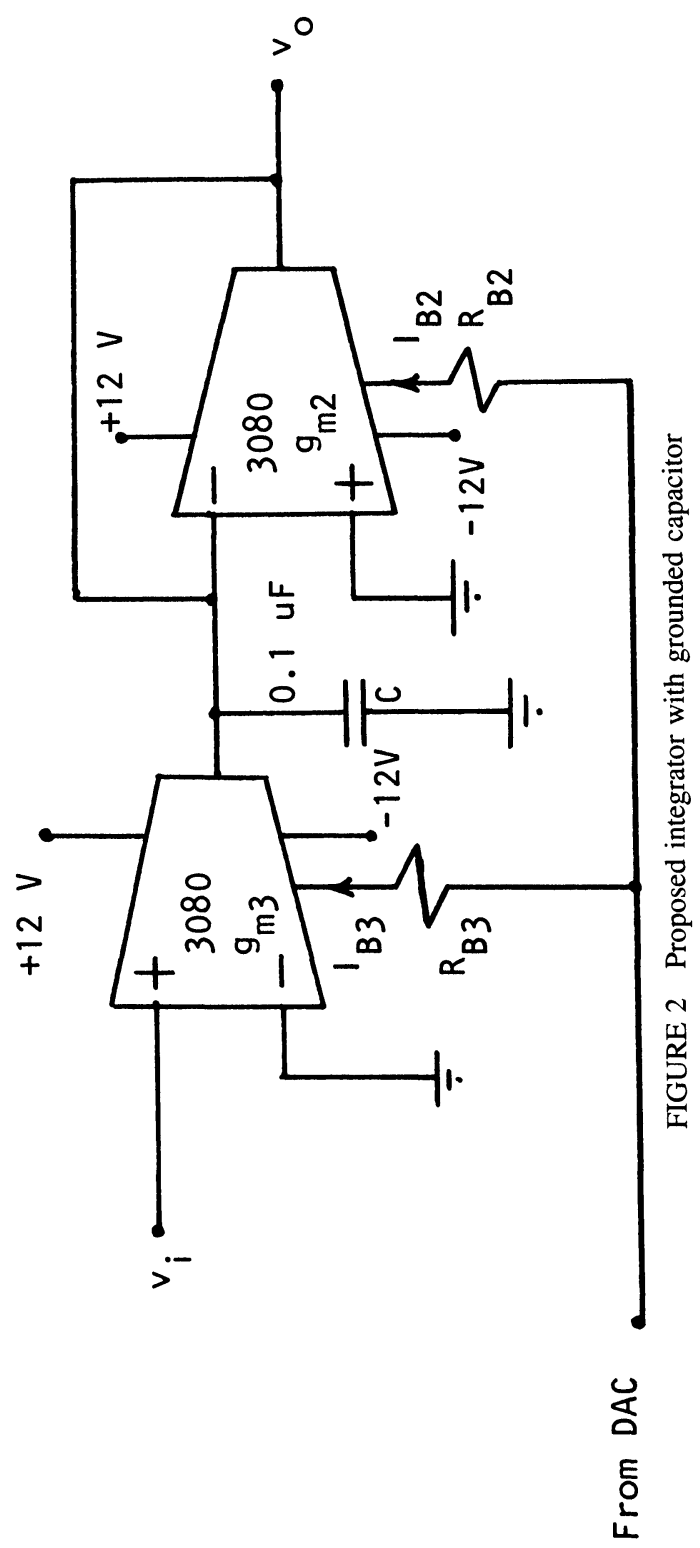




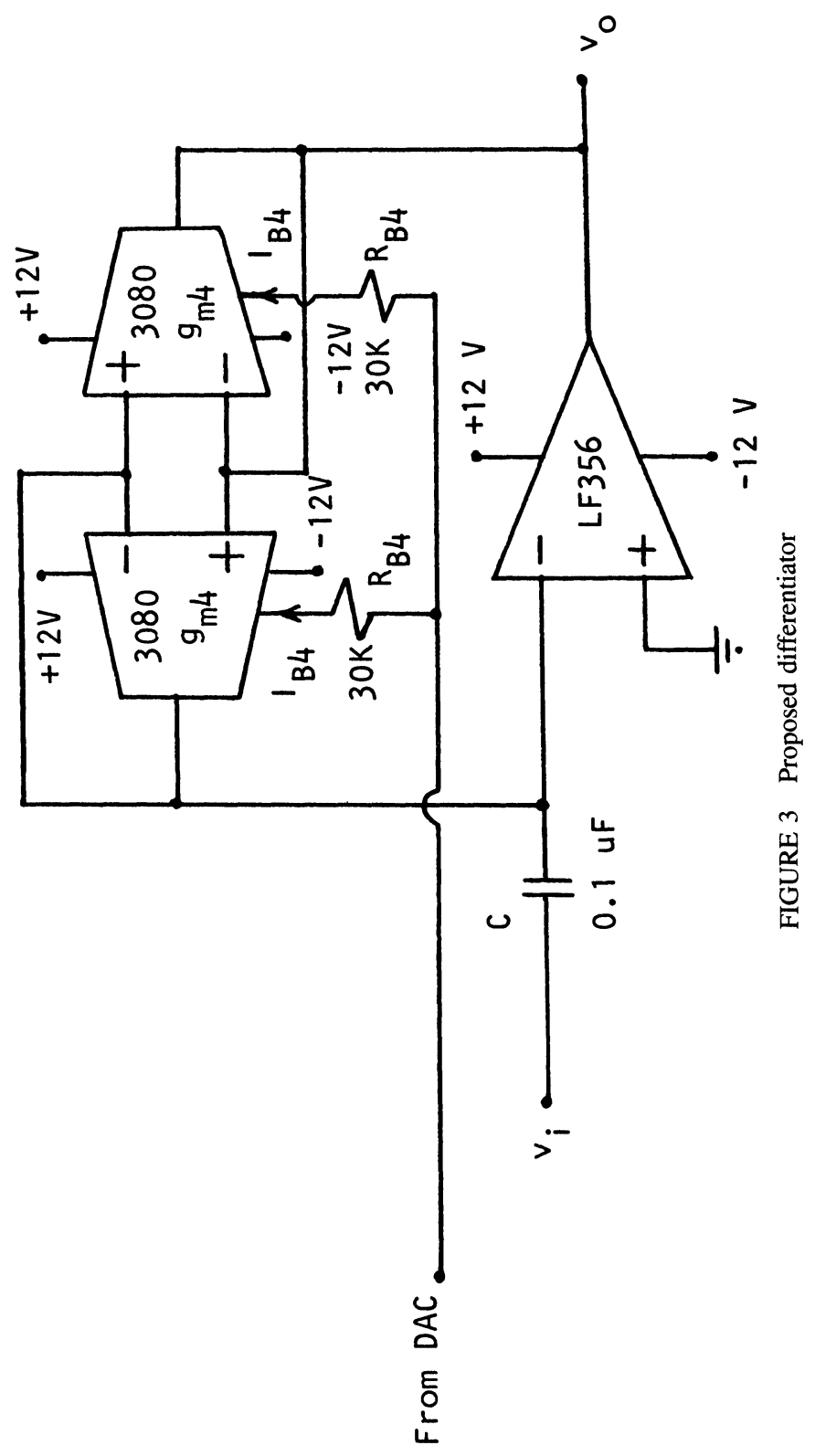




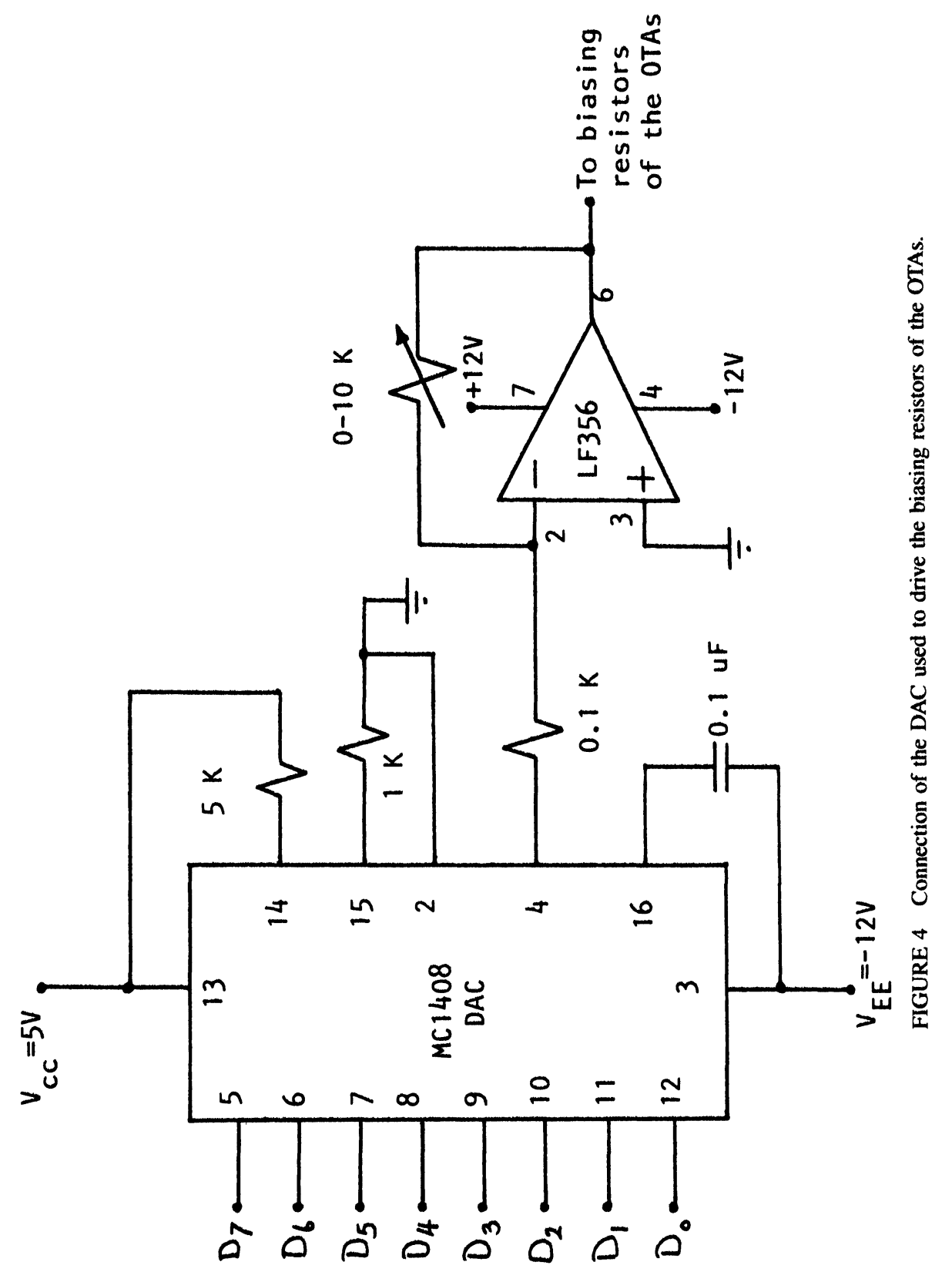




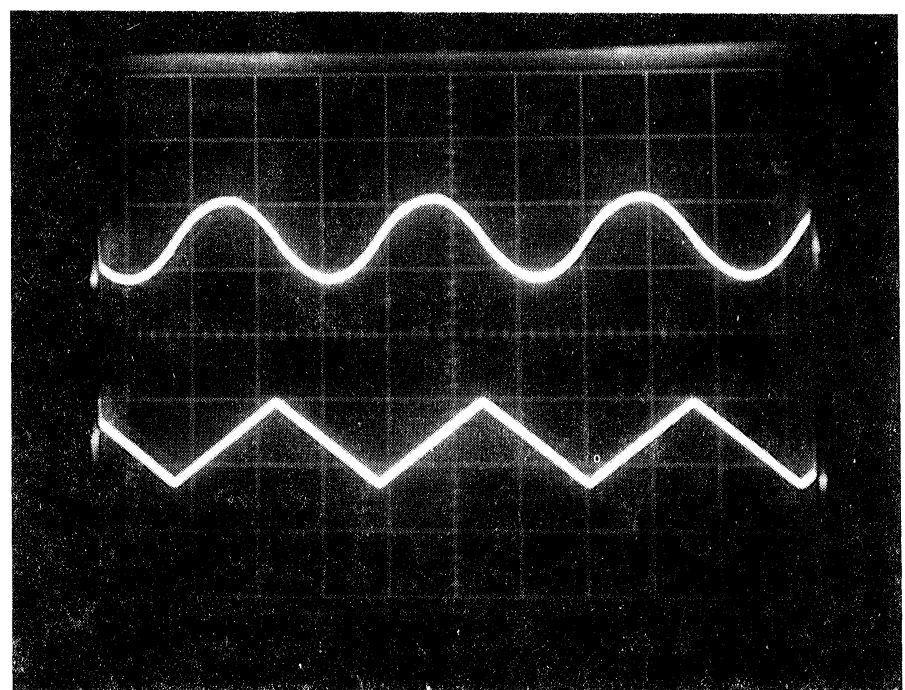

upper trace: input $60 \mathrm{mV}$ amplitude lower trace: Output $50 \mathrm{mV} / \mathrm{div}$

Frequency: $5 \mathrm{KHz}$

(a)

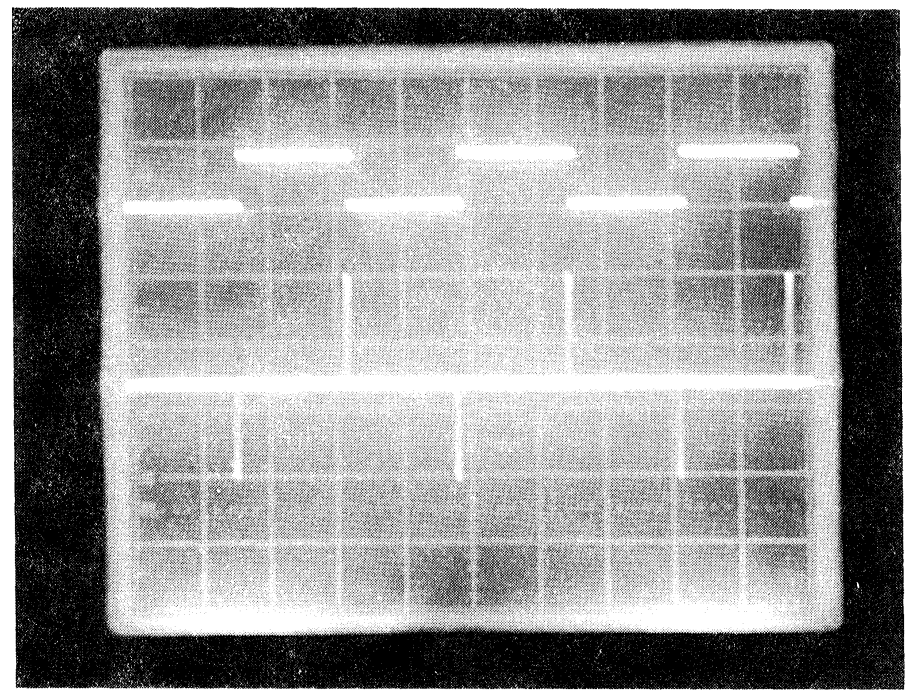

upper trace: input $20 \mathrm{mV}$ amplitude lower trace: output $0.5 \mathrm{~V} /$ division Frequency: $700 \mathrm{~Hz}$

(b)

FIGURE 5 Input and output waveforms obtained from the circuits of Figs. 2 and 3. 


\section{REFERENCES}

[1] R.L. Geiger and E.S. Sinencio, Active filter design using operational transconductance amplifiers: A tutorial, IEEE Circuits and Devices Magazine, Vol. 1, 1985, pp. 20-32.

[2] R. Senani, New electronically tunable OTA-C sinusoidal oscillator, Electronics Letters, Vol. 25, 1989, pp. 286-287.

[3] A.R. Saha, R. Nandi and S. Nandi, Integrable tunable sinusoidal oscillator using DVCCS, Electronics Letters, Vol. 19, 1983, pp. 745-746.

[4] R. Senani and B.A. Kumar, Linearly tunable Wien bridge oscillator realised with operational transconductance amplifiers, Electronics Letters, Vol. 25, 1989, pp. 19-21.

[5] M.T. Abuelma'atti and R.H. Almaskatti, Two new integrable active-C OTA-based linear voltage (current)-controlled oscillations, International Journal of Electronics, Vol. 66, 1989, pp. 135-138. 

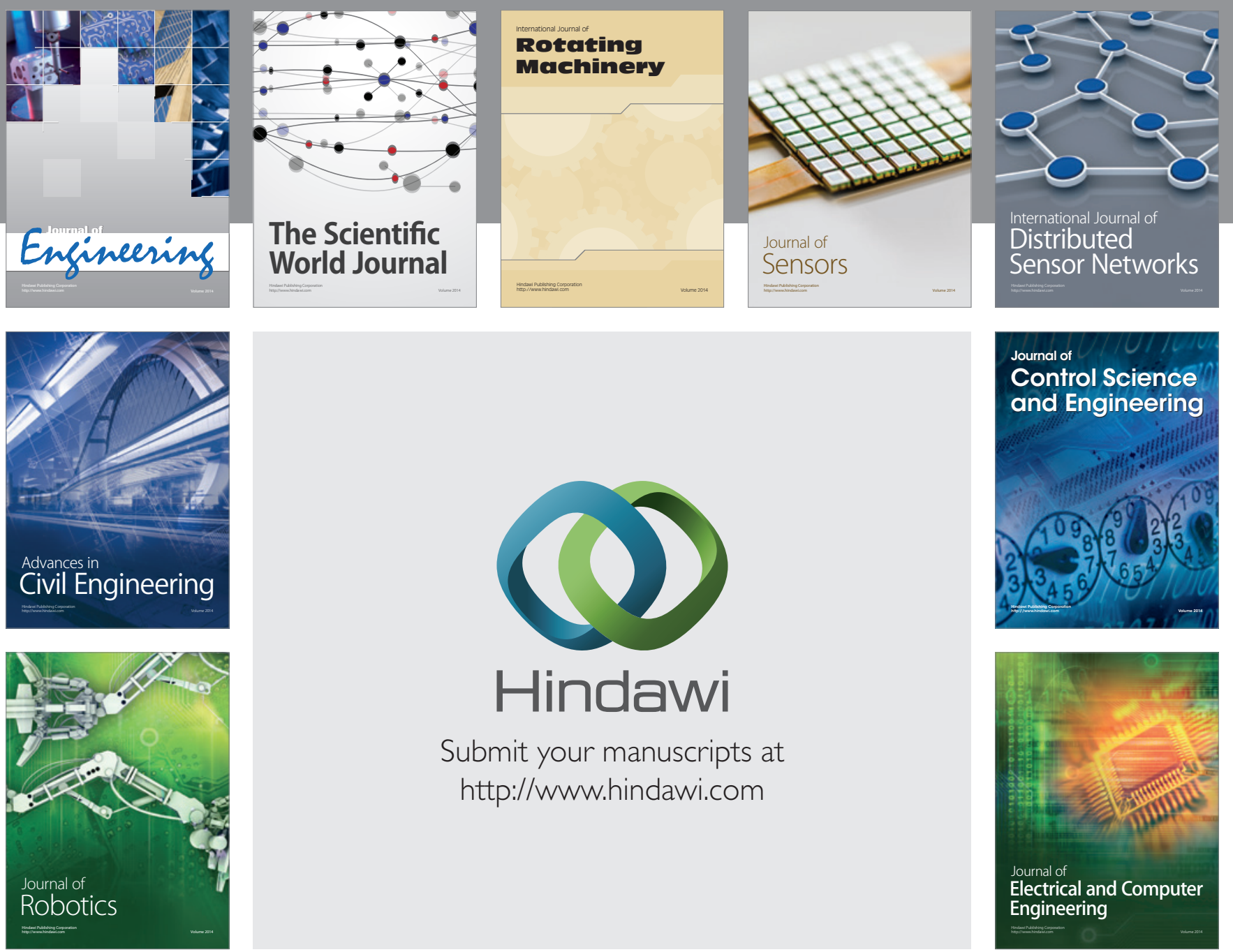

Submit your manuscripts at

http://www.hindawi.com
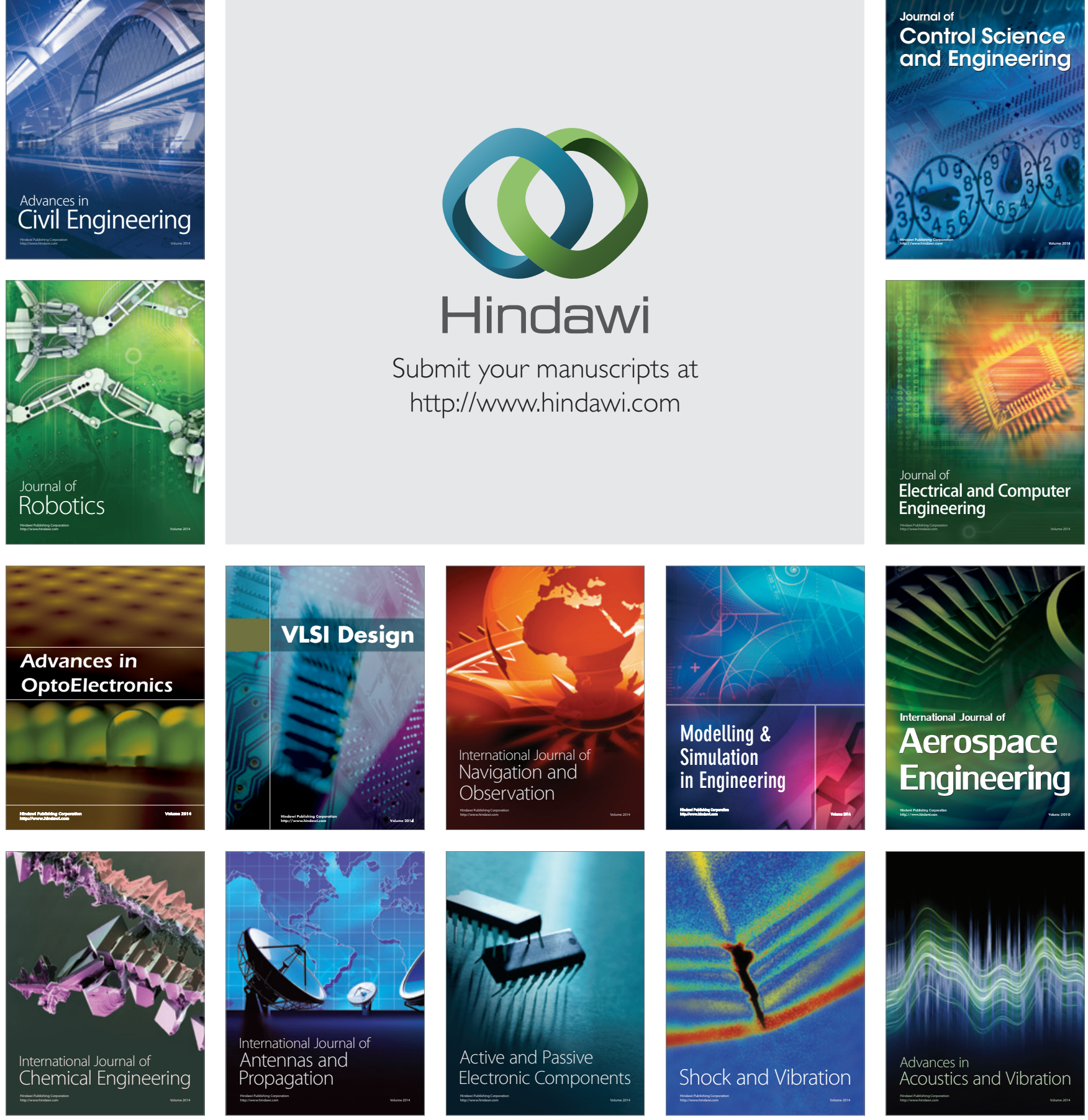